\title{
(2) OPEN ACCESS \\ Low-intermediate dose of lenvatinib in anaplastic thyroid cancer is highly effective and safe
}

\author{
Daniele Barbaro (1) , ${ }^{1}$ Paola Lapi, ${ }^{2}$ Paolo Viacava, ${ }^{2}$ Liborio Torregrossa ${ }^{3}$
}

${ }^{1}$ Department of Medicine, UO Endocrinology, USL North West Tuscany, General Hospital of Livorno, Livorno, Italy ${ }^{2}$ Department of Surgery, UO Pathology, USL North West Tuscany Office in Livorno, Livorno, Toscana, Italy ${ }^{3}$ Deparment of Surgery, UO Pathology, University of Pisa, Pisa, Toscana, Italy

Correspondence to Dr Daniele Barbaro; danielebarbar01970@libero.it

Accepted 12 November 2020

\section{SUMMARY}

We report two cases of anaplastic thyroid cancer (ATC) which had a very good response to a treatment with lenvatinib at $14 \mathrm{mg}$. A 73-year-old man with ATC stage IVB was operated on, undergoing a near-total thyroidectomy, and the pathological remnant tissue showed a quick and partial response to treatment with the drug. The patient had a single metastasis in the brain after 9 months, but then died due to bronchopneumonia after undergoing a neurosurgical intervention for the complete removal of the lesion. A 74-year-old woman with ATC stage IV was operated on, undergoing a neartotal thyroidectomy after a neoadjuvant treatment with the drug, that was continued after surgical treatment. She had a partial remission of the local disease and of distant metastasis, which lasted for 14 months. She then died 4 months later due to cancer progression. Lenvatinib at $14 \mathrm{mg}$ appears to be effective, fast and well tolerated.

\section{BACKGROUND}

Anaplastic thyroid cancer (ATC) is rare, but is one of the most aggressive cancers in humans. The standard treatment is surgical intervention, when possible, plus chemotherapy and accelerated hyperfractionated external beam radiotherapy (EBR), usually in combination. ${ }^{12}$ Despite this aggressive approach, prognosis is severe, and most of these cancers are metastatic at the initial diagnosis. Recently, targeted multi-tyrosine kinase (MTK) inhibitors have appeared to represent a further possibility for treatment to offer to these patients, and one of these, lenvatinib, has been approved in Japan for ATC (3-8). However, progression free survival (PFS) and overall survival (OS) in these patients, although dependent on stage, are still usually poor as regards any type of treatment, and, in fact, prognosis has not changed much over the last few years. We report an unusually long PFS and OS in two consecutive patients treated with a lowintermediate dose (14 mg) of lenvatinib, and speculate about possible explanations.

Check for updates

(c) BMJ Publishing Group Limited 2020. Re-use permitted under CC BY-NC. No commercial re-use. See rights and permissions. Published by BMJ.

To cite: Barbaro D, Lapi P, Viacava $\mathrm{P}$, et al. BMJ Case Rep 2020;13:e236934. doi:10.1136/bcr-2020236934

\section{CASE PRESENTATION}

\section{Case 1}

A 74-year-old male patient had already undergone a kidney transplant, and he was under treatment with everolimus and ciclosporin. He was in follow-up for inflammatory myofibroblastic tumour of the lung already treated by surgical intervention. During the follow-up, a CT/positron emission tomography (PET) showed a thyroid mass with high uptake (standardised uptake value/SUV 20.1)

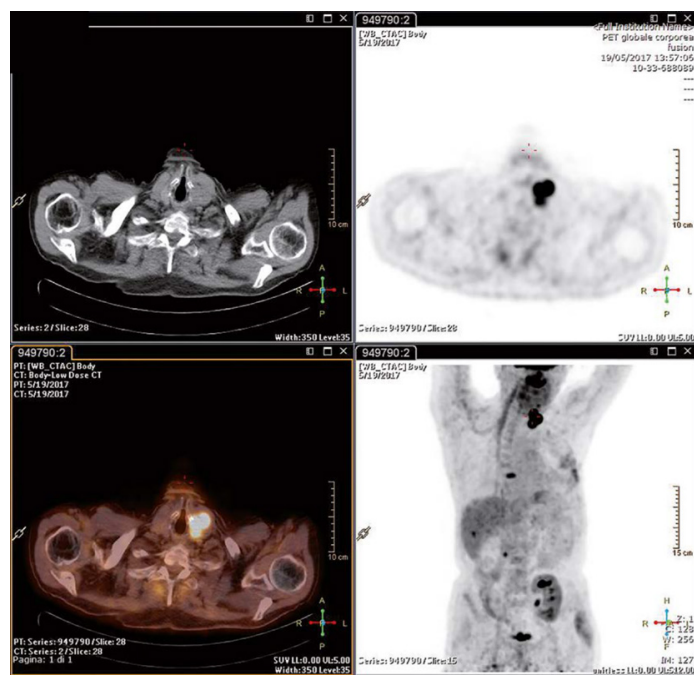

Figure 1 Whole body (18F)fluorodeoxyglucose positron emission tomography/CT before surgical intervention.

(figure 1). An ultrasonography confirmed a mass of 7.0 in maximum size in the left lobe and isthmus with a suspected lymph node metastases. A fine needle aspiration (FNA) was suspicious for ATC. The patient, after stoppage of everolimus, was sent for surgical treatment, and it was possible to perform a near-total thyroidectomy, leaving some paratracheal pathological tissue. The histology was: ATC with maximum size $7.5 \mathrm{~cm}$ involving the left and right lobe with spindle growth pattern, infiltrating perithyroidal muscles and oesophagus (immunophenotypic investigation showed CKAM

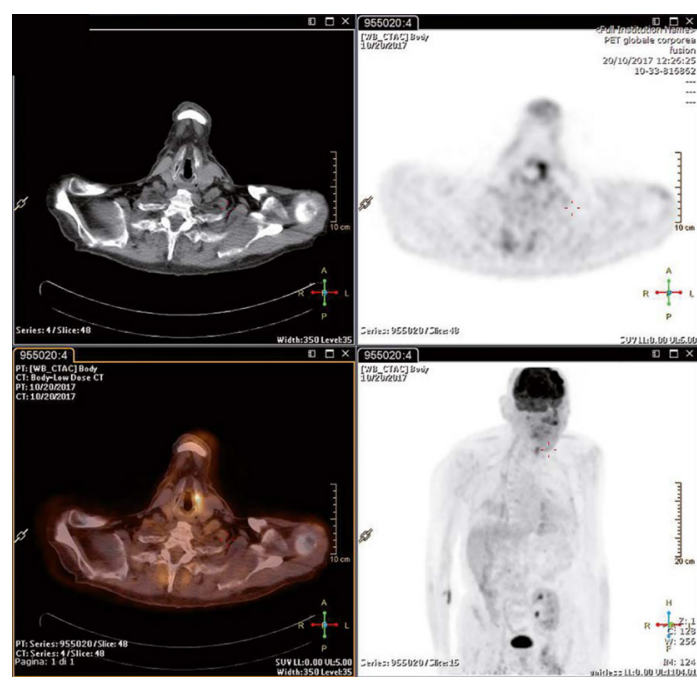

Figure 2 Whole body (18F)fluorodeoxyglucose positron emission tomography/CT after 3 weeks of treatment. 
Table 1 Molecular analysis was performed on DNA from formalin-fixed paraffin-embedded tissue

The targeted panel Myriapod NGS-LT 56G Onco Panel (Diatech Pharmacogenetics) was run on lon Torrent lon S5 platform (Thermo Fisher Scientific). Data were analysed by Myriapod NGS Data Analysis Software (Diatech Pharmacogenetics). The main hotspot regions in the below-mentioned genes were analysed.

\begin{tabular}{|c|c|c|c|c|c|c|c|}
\hline$A B L 1$ & CSF1R & FBXW7 & GNAS & KIT & NPM1 & \multicolumn{2}{|l|}{ SKT11 } \\
\hline AKT1 & CTNNB1 & FGFR1 & HNF1A & KRAS & NRAS & \multicolumn{2}{|l|}{ SMAD4 } \\
\hline$A L K$ & DOR2 & FGFR2 & HRAS & MAP2K1 & PDGFRA & \multicolumn{2}{|l|}{ SMARCB1 } \\
\hline$A P C$ & DNMT3A & FGFR3 & $I D H 1$ & MET & PIK3CA & \multicolumn{2}{|l|}{$S M O$} \\
\hline ATM & EGFR & FLT3 & $\mathrm{IDH} 2$ & MLH1 & PTEN & \multicolumn{2}{|l|}{$S R C$} \\
\hline BRAF & ERBB2 & FOXL2 & $J A K 2$ & $M L P$ & PTPN11 & \multicolumn{2}{|l|}{ TP53 } \\
\hline $\mathrm{CDH} 1$ & ERBB4 & GNA11 & $J A K 3$ & MSH6 & $R B 1$ & \multicolumn{2}{|l|}{ TSC1 } \\
\hline CDKN2A & $E Z H 2$ & GNAQ & $K D R$ & $\mathrm{NOTCH}$ & RET & \multicolumn{2}{|l|}{$V H L$} \\
\hline \multicolumn{8}{|c|}{ Patient 1 Ref.: I/23022/2017/LS2 } \\
\hline \multicolumn{8}{|c|}{ PASS VARIANTS } \\
\hline Gene & Variant classification & & cDNA change & Protein change & Allele frequency & \multicolumn{2}{|l|}{ ClinVar } \\
\hline TP53 & missense & & c.524G $>A$ & p.R175H & $63.70 \%$ & \multicolumn{2}{|c|}{ Pathogenic/likely pathogenic } \\
\hline PTEN & frameshift & & c.1048delA & p.T350fs & $5.30 \%$ & \multicolumn{2}{|l|}{ Not reported } \\
\hline \multicolumn{8}{|c|}{ LOW-QUALITY VARIANTS (confirmation by another tecnique is needed) } \\
\hline \multicolumn{2}{|l|}{ Gene } & $\begin{array}{l}\text { Variant } \\
\text { classification }\end{array}$ & CDNA change & Protein change & Allele frequency & ClinVar & WARNING \\
\hline \multicolumn{2}{|l|}{ RB1 } & nonsense & c. $763 \mathrm{C}>\mathrm{T}$ & p.R255* & $38.50 \%$ & Pathogenic & Strand bias \\
\hline \multicolumn{8}{|c|}{ Patient 2 Ref: I/3628/2018/LS3 } \\
\hline \multicolumn{8}{|c|}{ PASS VARIANTS } \\
\hline Gene & Variant classification & cDNA change & Protein change & Allele frequency & \multicolumn{3}{|l|}{ ClinVar } \\
\hline TP53 & missense & c. $839 \mathrm{G}>\mathrm{C}$ & p.R280T & $33.40 \%$ & \multicolumn{3}{|c|}{ Conflicting interpretations of pathogenicity } \\
\hline
\end{tabular}

'ClinVar' (https://www.ncbi.nlm.nih.gov/clinvar) refers to the clinical significance (described or predicted) of the variant (eg, pathogenic or likely pathogenic). 'Conflicting interpretations of pathogenicity' indicates controversial data in the literature.

*This sequence change creates a premature translational stop signal in the RB1 gene

5.2 positive, TTF1 and thyroglobulin negative), one lymph node with metastasis, pT4aN1bMx stage IVB TNM 2017 8th edition. Considering the general clinical context, after obtaining written consent for an off-label treatment, we decided to treat the patient with lenvatinib, and we chose as first line a medium-low dosage of $14 \mathrm{mg}$, which was initiated 7 days after the surgical intervention.

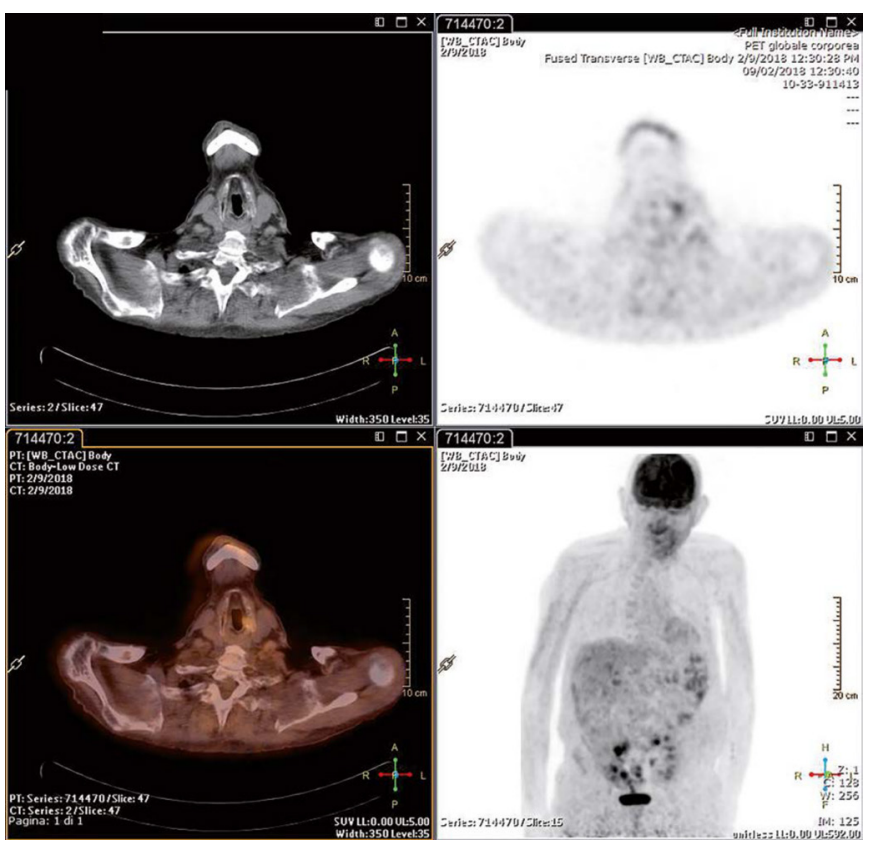

Figure 3 Whole body (18F)fluorodeoxyglucose positron emission tomography/CT after 8 months of treatment.
Molecular analysis of tumour pathological tissue was performed, and the data are reported in table 1.

\section{OUTCOME AND FOLLOW-UP}

After 3 weeks we performed a first (18-fluorodeoxyglucose (18FDG)) PET/CT, which showed a pathological tissue remnant with SUV 5.1 (figure 2). Ultrasonography showed only a small paratracheal pathological remnant tissue. Another (18FDG) CT/PET performed at 4 and 8 months, showed only minimal remnant tissue in the neck with a further reduced uptake, SUV

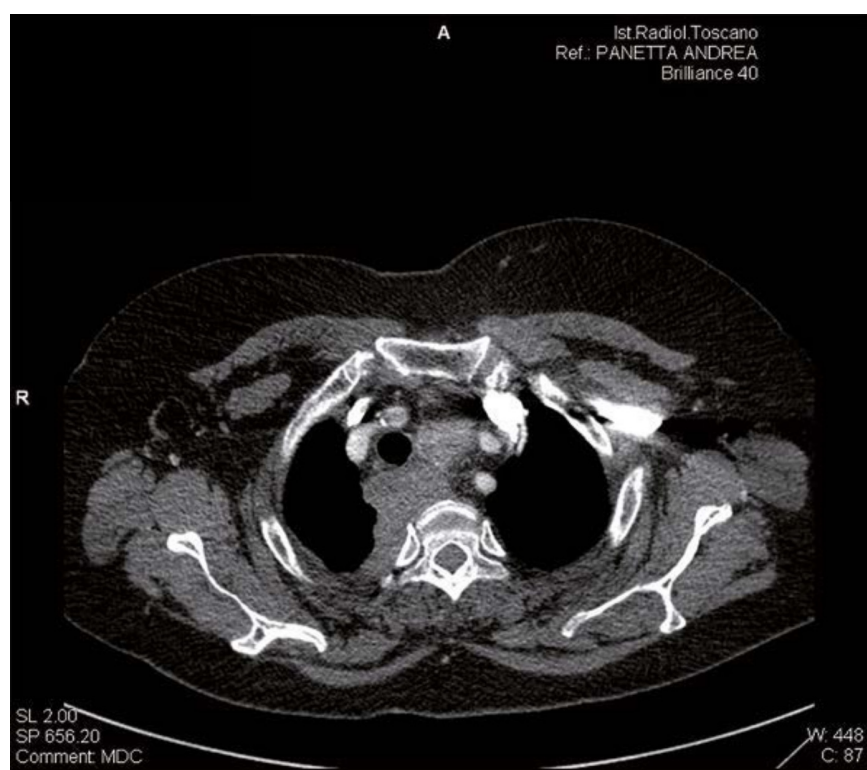

Figure 4 Chest CT scan at first staging. 


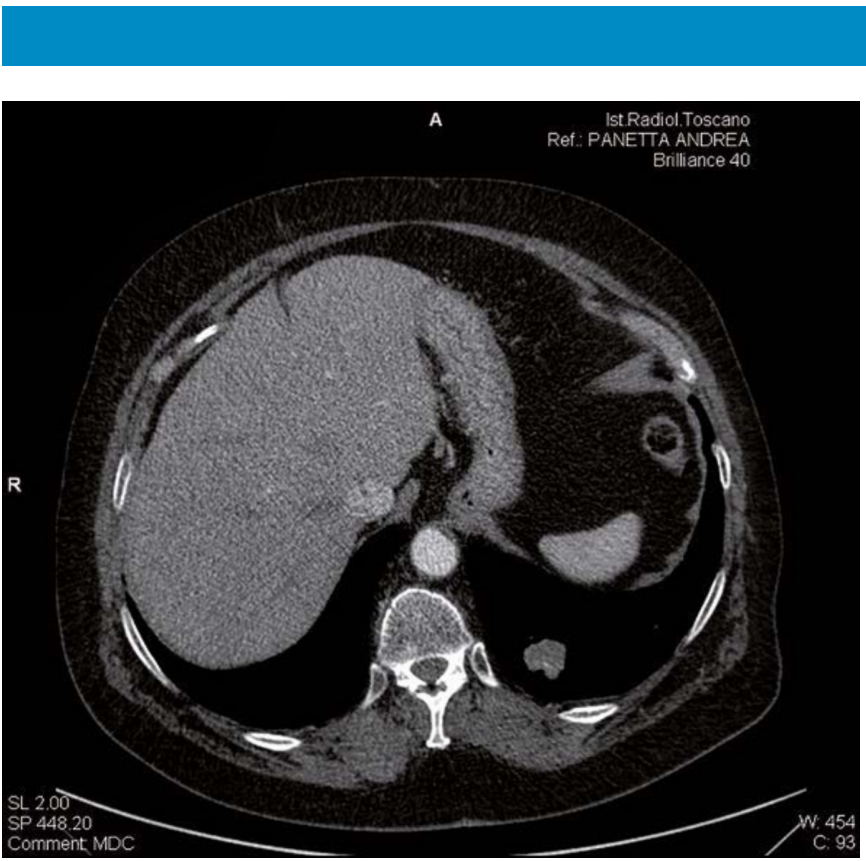

Figure 5 CT scan: prevalent lung metastasis at the first staging.

3.1 (figure 3). The patient was in good health, with an Eastern Cooperative Oncology Group (ECOG) score of 1-2. After 9 months, the patient had seizures, and an MRI showed a mass of $2 \mathrm{~cm}$ (a previous MRI 2 months before had been negative). The patient underwent neurosurgical intervention with complete removal of the lesion, but he passed away after 10 days due to bronchopneumonia.

\section{CASE PRESENTATION}

\section{Case 2}

A 73 -year-old female patient presenting with a rapidly growing goitre. At that moment the patient was in good health, and her ECOG score was 0. FNA was suspicious for ATC, and the patient underwent Computerized Tomography) (CT) total body, which showed a mass in the neck which extended into the mediastinum

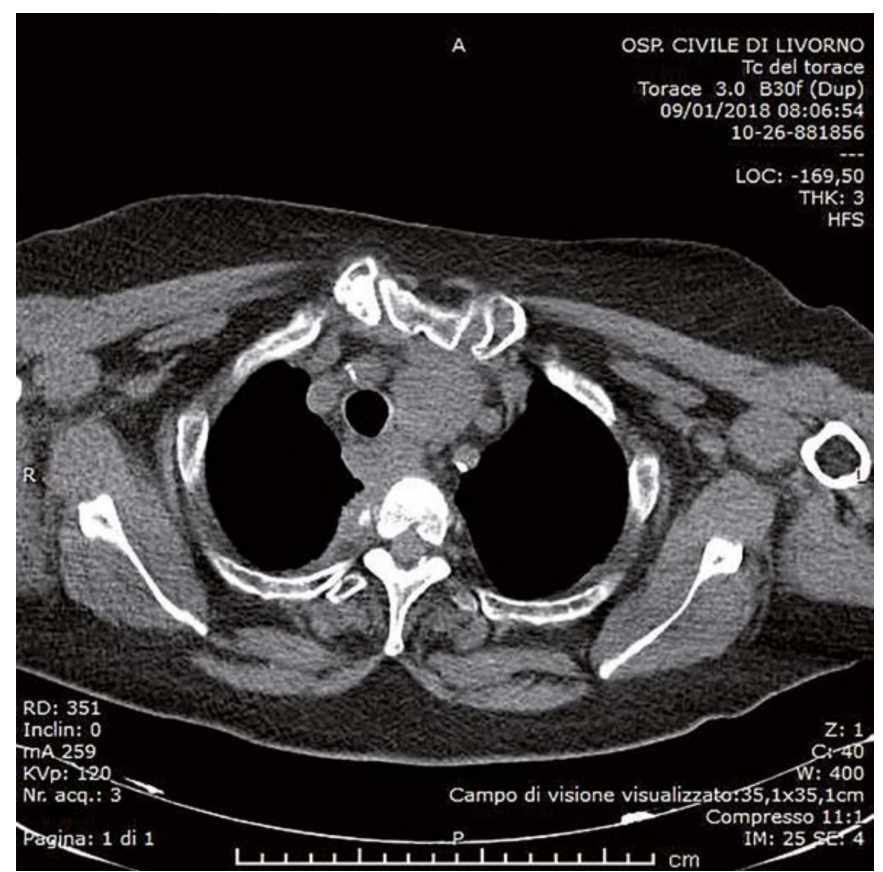

Figure 6 Chest CT scan after 3 weeks of treatment.

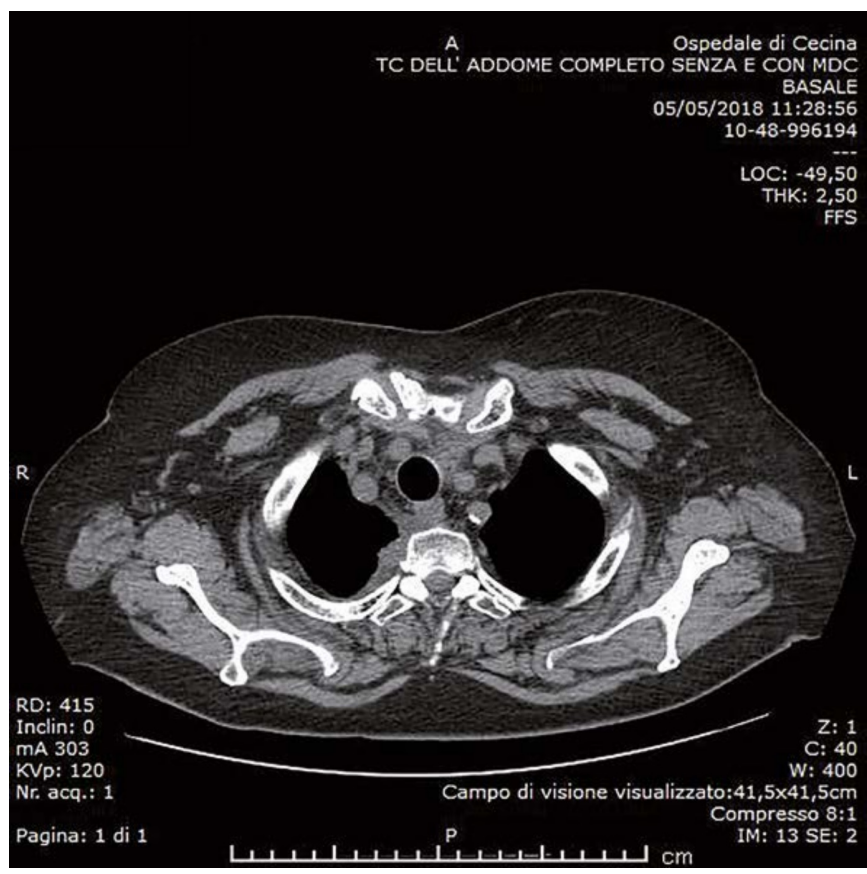

Figure 7 Chest CT scan after 12 months of treatment.

and apex of the lung, as well as lung metastases (figures 4 and 5 ). During staging, the patient showed not only a visible increase of the mass in the neck, but also a worsening of well-being, with diffuse pain in the chest and rapid deterioration of her clinical status. The patient was referred for surgical treatment, but she refused it, knowing the poor prognosis of the disease and the possibility that the intervention could be only a debulking with positioning of a tracheal cannula.

Molecular analysis of tumour pathological tissue was performed, and the data are reported in table 1 .

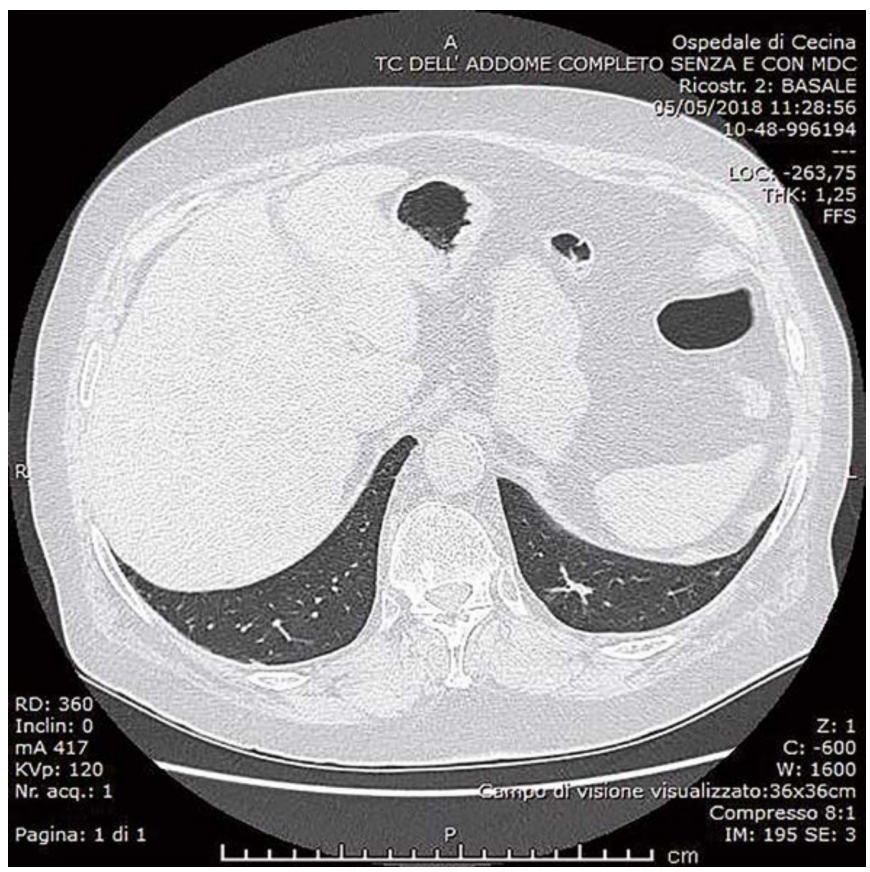

Figure 8 Chest CT scan with contrast medium: prevalent metastasis after 12 months of treatment. 


\section{OUTCOME AND FOLLOW-UP}

We decided, after written consent, for the off-label use of lenvatinib, and we started the drug at $14 \mathrm{mg} /$ day. At that moment ECOG was $1 / 2$. The patient did not show side effects, and experienced some improvement in quality of life in the first week regarding pain in the chest. A CT scan performed after 3 weeks showed a decrease in the mediastinal mass (figure 6). At this point we exerted great effort to convince the patient to submit to surgical treatment, and she agreed. The histology showed an ATC with a maximum size of $7 \mathrm{~cm}$ infiltrating perithyroid muscle TTF1, thyroglobulin, CD30 negative; CKCAM 5.2 positive, pT3bNxcM1 TNM 2017 8th edition stage IVC. During the following months, imaging showed a progressive remission of the disease up to almost complete remission (figures 7 and 8). After 14 months she experienced recurrence with unilateral palsy, and a CT scan showed progressive disease in the mediastinum and chest. Subsequently, the patient developed bilateral recurrent palsy, and underwent a tracheostomy. Exitus occurred after 4 months.

\section{DISCUSSION}

ATC is one of the most malignant solid tumours in humans. The prognosis is usually so poor that there is not any real guideline regarding treatment, although surgical intervention is usually considered the first line of treatment. ${ }^{12}$ It can have a debulking aim, or, rarely, offer a possibility of radicality in less advanced cases, and sometimes surgical treatment can follow an attempt of neoadjuvant medical treatment. The type of medical treatment, alone or combined with EBR, still represents a matter for discussion, and among medical treatments, some MTK inhibitors, already approved for iodine refractory differentiated thyroid cancer, have garnered interest. Among these, lenvatinib is known to be directed against FGR 1, 2, 3, 4; VEGFR 1, 2, 3; PDGFRb; RET and c-Kit, and it has been successfully employed in iodine refractory thyroid cancer. ${ }^{3}$ Lenvatinib has been approved also for treatment of ATC, in Japan in 2015, and there are now several reports regarding this drug. ${ }^{4-9}$ However, in advanced stages IVB and IVC, as in our cases, the PFS and OS are usually poor. The various published papers have shown a median of PFS and OS ranging, respectively, from 4.0 to $4.2,{ }^{5}$ and 7.4 to 10.6 months. ${ }^{56}$ The best results appear to be those of a phase II study. ${ }^{5}$ However, in this study a partial response was seen in only $24 \%$ of cases, and only 4 patients out of 17 were able to complete the study, either because they did not show a response, or because they developed severe side effects to the treatment at the initial dose of $24 \mathrm{mg}$. In this last study, the patients enrolled had as a criterion of inclusion that they were expected to survive at least 8 weeks or more after the first dose of lenvatinib, so we must also suppose that their clinical condition was not so bad. The stage for all patients was between IVA and IVC, but it was not reported which cases were able to finish the study and showed the best results.

Our cases offer interesting points for speculation. In our first case, we had a PFS of 8 months, and the recurrence of disease was in the brain. There are no data regarding the crossing of lenvatinib through the blood-brain barrier, but as regards other MTK inhibitors we can suppose a reduced transfer in the brain, and therefore a reduced concentration and activity at this level. ${ }^{10-13}$ On the other hand, no locoregional recurrences in other sites of the body were present. Rather, lenvatinib appeared to exert very good locoregional control, inasmuch as CT/PET showed a very remarkable reduction of FDG uptake in the neck. The overall survival was 10.2 months, but it could have been much longer if the patient had not passed away because of bronchopneumonia, due likely to the immunosuppressive treatment, since the neurosurgical intervention removed completely the metastasis. The second case appears even more surprising, considering the stage and the general clinical condition. We had a PFS of 14 months, with an OS of 18 months, and a partial remission which came very near to a complete remission. Both patients tolerated quite well the starting dose of $14 \mathrm{mg}$, considering the fact that the side effects were related to the dose and to the serum levels. ${ }^{14-16}$

An initial speculation could be that in the complex mechanism of the regulation of the various MTK cascades, there could exist a specific, most effective dose, beyond which a hook effect occurs, and the efficacy may decrease. Although data in vitro show that the effects on ATC cells of lenvatinib are dose dependent, ${ }^{17} 18$ no study, in point of fact, reports if there might exist something like this hook effect for an increasing dose of the drug. If we analyse all the cases reported in the literature, we find only two cases comparable both for advanced stage and for PFS (9.0 and 27.9 months) ${ }^{3}$; also in these series some patients were treated with $14 \mathrm{mg}$ for a progressive reduction of the drug, but, unfortunately, in that paper it is not specified which dose these two cases were treated with.

We could also speculate that in our cases we enjoyed such a good response because the dose of lenvatinib was not very high, and was hence well tolerated by the patients, who could continue without important side effects, being that side effects were related to the oral dose. ${ }^{14-16}$ However, the response was not only long-lasting, but also fast, showing powerful activity of the $14 \mathrm{mg}$ of lenvatinib. Regarding the first hypothesis, that there is the possibility that this intermediate dose might exert some special activity on ATC, studies in vitro will help to show the dose/activity profile of the drug. As already stated, some studies exist showing a dose-dependent activity. ${ }^{17} 18$ However, higher concentrations will have to be studied, even though we have to keep in mind that studies in vitro on ATC cells cannot represent the reality in vivo, since lenvatinib exerts a fundamental action also on the vessels by Vascular Endothelial Growth Factor .

Regarding molecular analysis, our data do not appear to show any special predictive mutation for a better response.

In conclusion, in our two consecutive cases treated by lenvatinib, we enjoyed a very good response using $14 \mathrm{mg}$. Further studies in vitro and clinical trials should be encouraged to test lenvatinib in ATC using lower doses than the standard $24 \mathrm{mg}$ dose. From a practical point of view, we could suggest trying

\section{Learning points}

- Diagnosis of anaplastic thyroid cancer (ATC) is usually histological. However, in special cases a cytology examination by an expert pathologist can be sufficient (case 2).

- Lenvatinib at low-medium dosage (14 mg in our cases) has been demonstrated to be highly effective and quick in controlling the disease. Two possible explanations can be speculated on: simply that this lower dose can allow a better treatment of patients because of the absence of important side effects in such critical patients, or that an especially powerful activity of an intermediate dosage is exerted on the complex balance of multi-tyrosine kinase cascade in ATC.

- Research in vitro and clinical trials could help to elucidate the hypothesis that a lower dosage could be more effective than a full standard dose in this cancer.

- Lenvatinib can have a neoadjuvant role (case 2). 
to use this particular dose $(14 \mathrm{mg})$ as a starting dose in such critical patients with ATC, since the drug is effective, the action is fast, and side effects are seen to be less frequent and more manageable.

Contributors DB: writing of the manuscript. PL: references and editing figures. PV: cytology. LT: histology and molecular biology.

Funding The authors have not declared a specific grant for this research from any funding agency in the public, commercial or not-for-profit sectors.

Competing interests None declared.

Patient consent for publication Obtained.

Provenance and peer review Not commissioned; externally peer reviewed.

Open access This is an open access article distributed in accordance with the Creative Commons Attribution Non Commercial (CC BY-NC 4.0) license, which permits others to distribute, remix, adapt, build upon this work non-commercially, and license their derivative works on different terms, provided the original work is properly cited and the use is non-commercial. See: http://creativecommons.org/ licenses/by-nc/4.0/.

ORCID iD

Daniele Barbaro http://orcid.org/0000-0002-1474-7178

\section{REFERENCES}

1 Smallridge RC, Ain KB, Asa SL, et al. American thyroid association guidelines for management of patients with anaplastic thyroid cancer. Thyroid 2012;22:1104-39.

2 Ferrari SM, Elia G, Ragusa F, et al. Novel treatments for anaplastic thyroid carcinoma. Gland Surg 2020;9:S28-42.

3 Schlumberger $\mathrm{M}$, Tahara $\mathrm{M}$, Wirth $\mathrm{L}$, et al. Lenvatinib versus placebo in radioiodinerefractory thyroid cancer. N Engl J Med 2015;372:621-30.

4 Iwasaki H, Toda S, Suganuma N, et al. Lenvatinib vs. palliative therapy for stage IVC anaplastic thyroid cancer. Mol Clin Oncol 2020;12:138-43.
5 Tahara M, Kiyota N, Yamazaki T, et al. Lenvatinib for anaplastic thyroid cancer. Front Oncol 2017;7:25

6 Iwasaki $\mathrm{H}$, Yamazaki $\mathrm{H}$, Takasaki $\mathrm{H}$, et al. Lenvatinib as a novel treatment for anaplastic thyroid cancer: a retrospective study. Oncol Lett 2018;16:7271-7.

7 Takahashi S, Kiyota N, Yamazaki T, et al. A Phase II study of the safety and efficacy of lenvatinib in patients with advanced thyroid cancer. Future Oncol 2019;15:717-26.

8 Iñiguez-Ariza NM, Ryder MM, Hilger CR, et al. Salvage lenvatinib therapy in metastatic anaplastic thyroid cancer. Thyroid 2017;27:923-7.

9 Oishi K, Takabatake D, Shibuya Y. Efficacy of lenvatinib in a patient with anaplastic thyroid cancer. Endocrinol Diabetes Metab Case Rep 2017;2017:16-136.

10 Lagas JS, van Waterschoot RAB, Sparidans RW, et al. Breast cancer resistance protein and P-glycoprotein limit sorafenib brain accumulation. Mol Cancer Ther 2010;9:319-26.

11 Thanasupawat T, Natarajan S, Rommel A, et al. Dovitinib enhances temozolomide efficacy in glioblastoma cells. Mol Oncol 2017;11:1078-98.

12 Laramy JK, Kim M, Parrish KE, et al. Pharmacokinetic assessment of cooperative efflux of the multitargeted kinase inhibitor ponatinib across the blood-brain barrier. J Pharmacol Exp Ther 2018;365:249-61.

13 Kort A, Durmus S, Sparidans RW, et al. Brain and testis accumulation of regorafenib is restricted by breast cancer resistance protein (BCRP/ABCG2) and P-glycoprotein (P-GP/ABCB1). Pharm Res 2015;32:2205-16.

14 Nagahama M, Ozeki T, Suzuki A, et al. Association of lenvatinib Trough plasma concentrations with lenvatinib-induced toxicities in Japanese patients with thyroid cancer. Med Oncol 2019:36:39.

15 Hussein Z, Mizuo H, Hayato S, et al. Clinical pharmacokinetic and pharmacodynamic profile of lenvatinib, an orally active, small-molecule, multitargeted tyrosine kinase inhibitor. Eur J Drug Metab Pharmacokinet 2017;42:903-14.

16 Inoue K, Asai N, Mizuo H, et al. Unique metabolic pathway of [(14)C]lenvatinib after oral administration to male cynomolgus monkey. Drug Metab Dispos 2012;40:662-70.

17 Ferrari SM, La Motta C, Elia G, et al. Antineoplastic effect of lenvatinib and vandetanib in primary anaplastic thyroid cancer cells obtained from biopsy or fine needle aspiration. Front Endocrinol 2018;18:764.

18 Ferrari SM, Bocci G, Di Desidero T, et al. Lenvatinib exhibits antineoplastic activity in anaplastic thyroid cancer in vitro and in vivo. Oncol Rep 2018;39:2225-34.

Copyright 2020 BMJ Publishing Group. All rights reserved. For permission to reuse any of this content visit

https://www.bmj.com/company/products-services/rights-and-licensing/permissions/

BMJ Case Report Fellows may re-use this article for personal use and teaching without any further permission.

Become a Fellow of BMJ Case Reports today and you can:

- Submit as many cases as you like

- Enjoy fast sympathetic peer review and rapid publication of accepted articles

- Access all the published articles

Re-use any of the published material for personal use and teaching without further permission

Customer Service

If you have any further queries about your subscription, please contact our customer services team on +44 (0) 2071111105 or via email at support@bmj.com.

Visit casereports.bmj.com for more articles like this and to become a Fellow 